\title{
INFLUÊNCIA DA LAVAGEM UTERINA NOS ÍNDICES DE CONCEPÇÃO PÓS-PARTO EM ÉGUAS PURO-SANGUE DE CORRIDA
}

\author{
EFFECTS OF UTERINE FLUSHING ON POST-PARTUM CONCEPTION RATE IN THROUGHBRED MARES
}

Neiva Medianeira DEPRÁ'; Joaquin Lopez de ALDA'; Inês Nicoloso de CASTRO2; Karin Erica BRASS3; Flávio Desessards De La CÔRTE4; Carlos Antônio Mondino SILVA

\begin{abstract}
RESUMO
Avaliou-se o efeito da lavagem uterina pós-parto com solução de $\mathrm{NaCl}$ a $0,9 \%$ ou iodo-povidine a $0,4 \%$ em éguas Puro-Sangue de Corrida (PSC), em relação aos índices de concepção pós-parto (p.p.). Foram comparadas as taxas de concepção de 27 éguas, sem qualquer manipulação uterina (Controle). 57 éguas com solução de $\mathrm{NaCl}$ (I). 36 éguas com jodopovidine (II) e 15 éguas apresentando retenção de placenta, que sofreram lavagem uterina com as duas soluções. Concluiu-se que as lavagens uterinas p.p., independentemente da substância utilizada, influenciaram negativamente a involução e a preparação do útero para a concepção, só estando indicadas em éguas com retenção de placenta, desde que aplicadas até o $3^{\circ}$ ou $4^{\circ}$ dia p.p.
\end{abstract}

UNITERMOS: Éguas; Lavagem uterina; Concepção pós-parto

\section{INTRODUÇÃO}

A égua se caracteriza por apresentar um intervalo reduzido entre o parto e a primeira ovulação. O primeiro cio já aparece entre o $6^{\circ}$ e o $18^{\circ}$ dia pós-parto (p.p.). Por isso, na égua, a involução uterina deve ser um processo rápido e eficiente para que se possam alcançar bons índices de concepção.

A maioria das éguas que não concebem no "cio do potro" apresentam uma involução uterina mais lenta, não alcançam uma rápida limpeza física do espaço uterino, têm presença mais prolongada de debris celulares e um aumento da flora bacteriana e do número de neutrófilos e linfócitos no lúmen uterino (SALTIEL et al.6, 1987). O aporte elevado de neutrófilos para a mucosa uterina parece levar a uma redução da eficiência da limpeza endometrial e dos índices de concepção devido à ação citotóxica dos neutrófilos sobre os gametas e embriões (WATSON' ${ }^{9}, 1988$ ).

Entre as possibilidades descritas na literatura para acelerar a involução uterina p.p. e incrementar a fertilidade, foram propostas as lavagens uterinas para, a par da retirada mecânica das secreções e debris, elevar a contratilidade miometrial, provocando uma "limpeza" mais eficiente do útero (McCUE; HUGHES?3, 1990).
No intuito de testar a efïciência dessas lavagens uterinas, durante três temporadas de monta avaliou-se sua influência nos índices de concepção p.p., comparando-se lavagens efetuadas com solução salina de $\mathrm{NaCl}$ a $0.9 \%$ ou com iodopovidine a $0.4 \%$ a um grupo controle no qual não houve qualquer manipulação uterina no período p.p.; paralelamente, observou-se o efeito das lavagens uterinas em éguas que sofreram Retentio secundinarum.

\section{MATERIAL E MÉTODO}

O experimento foi desenvolvido no Haras Santa Maria de Araras, localizado em São José dos Pinhais - PR, durante três temporadas de monta, utilizando-se 135 éguas PSC, com idade variando entre 4 e 17 anos.

Os animais foram divididos primeiramente em três grupos:

Grupo I - 57 éguas, com idade entre 4 e 16 anos, submetidas a lavagens uterinas com aproximadamente 5 litros de solução de $\mathrm{NaCl}$ a $0,9 \%$ *

Grupo II - 36 éguas com idade entre 4 e 15 anos, submetidas a lavagens com solução de iodo-povidine** a $0,4 \%$, diluída em salina $0.9 \%$.

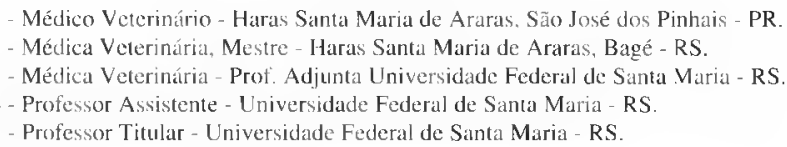




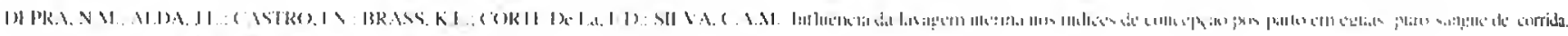

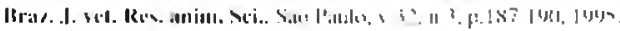

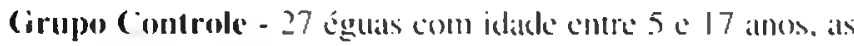
guais llako horam submedidas a quatyucr lavagem uterina.

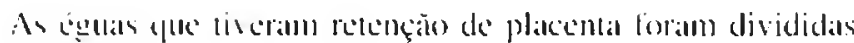
cill:

Grupo III - I I éguas com idade entre 6 e 12 amos, submedi-

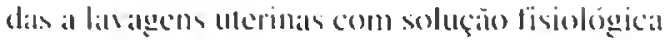

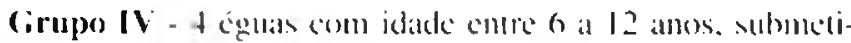

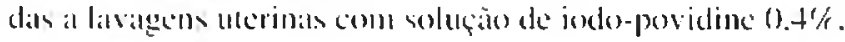

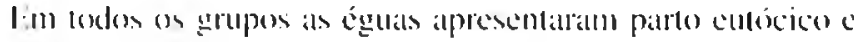
observou-se o lempor de climinaçäo da placenta.

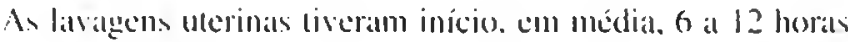
p.p.. uma ver alo dial, allé a recuperação de conteúdo uterino de aspecto limpido ce lranvlícido.

1 partir do 6" dia p.p. als éguas cram rufiadas e. quando apresentaliam simais de cio, eram submetidas al palpaçaio retal to a ultra-sonografiat: para avaliar o grau do involuçăo ulerina é atividade ovariana. As éguals eram cobertas mo momento matis proximo da ovulaçăo. A detecęão da ovulação for lèla através de palpação retal o ultri-sonografia. 48 horas após a cobertura.

() primeiro diagnóstien de gestação foi feito altravés de pal.

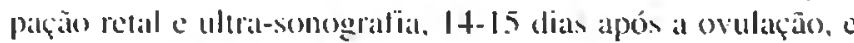
comlirmado aos 21, 30. 45 a 60 dias. As éguas que não concebiam no "cio do potro" eram novamente submeticlas a coberturas mos cios subsecuécotes. Os dados deste estudo foram subutictidos alo kessc $x^{2}$ (qui-quadratdo)

\section{RESULAAI)S}

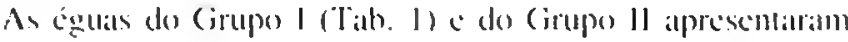

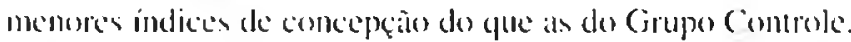

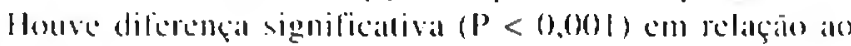

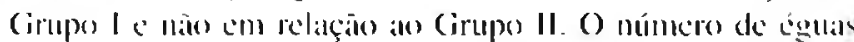
gestanter mos (ifupos 1 e ll foi mator no $2 "$ e no 3 " cio p.p.

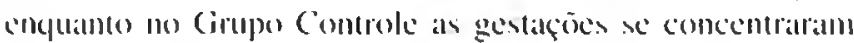

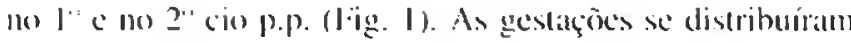
a10 longo dos 5 cion p.p. nos cirupos 1 e 11 e no (jrupu

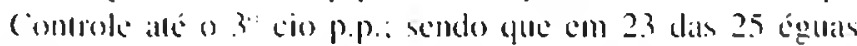

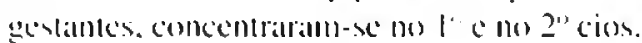

\section{TABE:I,A I}

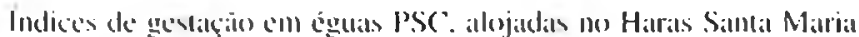

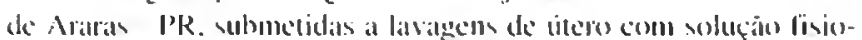

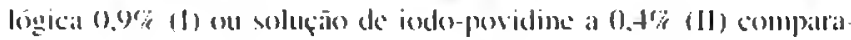

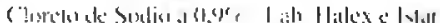

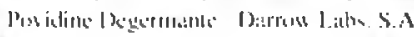

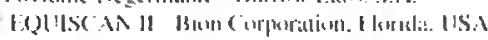

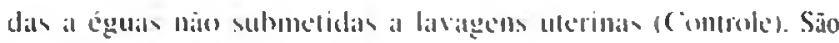

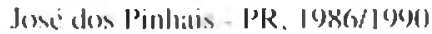

\begin{tabular}{|c|c|c|c|c|c|c|c|c|c|}
\hline \multirow[t]{2}{*}{ (ilup) } & \multirow{2}{*}{$\begin{array}{c}\text { loguas } \\
n\end{array}$} & \multirow{2}{*}{ 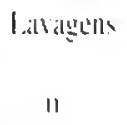 } & \multicolumn{5}{|c|}{ 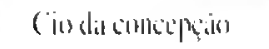 } & \multicolumn{2}{|c|}{ 'lintil } \\
\hline & & & l" & $2 *$ & $i^{\prime \prime}$ & $4^{\prime \prime}$ & 5 & (i & $V$ \\
\hline I & 57 & $1-6$ & (11) & 19) & (x) & 115 & 111 & 4 & 1.3 \\
\hline$\dot{H}$ & $1(11)$ & & 17 & 32 & 10 & (II) & (1) & 77 & 23 \\
\hline II & 36 & 10 & 11 & 10 & 117 & (1) & (1) & 3 & 0.5 \\
\hline$\%$ & 1010 & & 30 & אי & (4) & 110 & 113 & 80 & 14 \\
\hline Comtroles & 27 & & 1.1 & (11) & 112 & & & 25 & 02 \\
\hline$\gamma$ & $10(1)$ & & 52 & 33 & 7.5 & & & (4) & 7.5 \\
\hline
\end{tabular}

(i: gestillute: V: valiak. (1'<0.00)

Sas éguas com retençäo de placenta. lanto nacyuclas laviadas com solução salina lïsiológeca (Tah. 2) quamto nas lavadas com iodo-povidine, observou-se uma redaçăo do númoro de gestantes em relação às que năo apresentaram retenção. A concepcẹio a a gestaçäo distributram-se independentemente do lempo de relenção. com exceçấn de uma égua do (jrupo do jodo-povidine $0.4 \%$. com relchęào de placental por 24 horas. Por oulro lado, verificou-se yut a relenção de plaxentla ocorreu. da mesma forma. com lodos os grupon clários.

\section{TAlBEI.A 2}

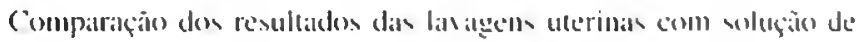
$\mathrm{NaCl}$ a $0.9 \%$ (III) ou iodo-ponidine al $0.1 \%$ (IVI cm éguats PSC

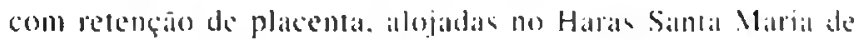

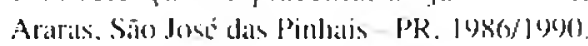

\begin{tabular}{|c|c|c|c|c|c|c|c|c|c|c|}
\hline \multirow[t]{2}{*}{ Trial. } & \multicolumn{2}{|c|}{ |: } & \multirow{2}{*}{ 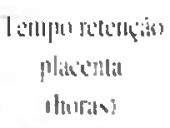 } & \multicolumn{5}{|c|}{ ( in dis conkeprions } & \multicolumn{2}{|c|}{ Tiutial } \\
\hline & $\because$ & follins & & $1^{*}$ & $\because$ & $\therefore$ & $\because$ & 5 & (i & 1 \\
\hline III & 11 & $\dot{s}$ & 5 & (1) & $11 i$ & $11:$ & (in) & 1111) & $19 ?$ & it: \\
\hline$\because$ & $\ln (n)$ & & & IN & 37 & $1, k$ & & & 6 & $9 \bar{i}$ \\
\hline Ir & (1) & $?$ & (1:3) & (H) & $0 i$ & 101 & (I) & ing & $0 i$ & ill \\
\hline 'i & $\mid(x)$ & & & & 75 & & & & 75 & $2 i$ \\
\hline linlial & 15 & & & II? & on & 11: & (iv) & 010 & I11 & iis \\
\hline 4 & $(x)$ & & & $1 ;$ & III & $1: 3$ & & & of & it \\
\hline
\end{tabular}

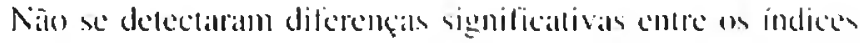

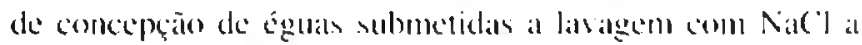
$0.9 \%$ e iodo-poridine a $0.4 \%$.

\section{ISTCLSSAO}

Verificou-se que lanto as éguas que foram lavadas com salina lisiológical (Grupo I) quanto an que o loram com iodo-posidine (Cirupo Il) aprexentatam pereentual de gestaçäo reduri. do em comparaçào an controle. especialmente no l" cio 


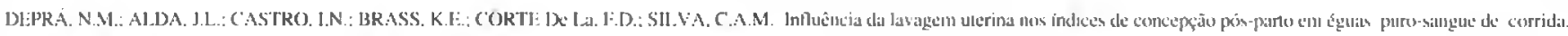
Braz. J. vel. Ke's. anim. Sci. Sim Paulu. 4.32. 11,3. p. 187-190. 1905

p.p.. ou "cio do potro". Neste cio alcançou-se percentagem de prenhez três vezes mais elevada nas éguas Controle que nas do Grupo I e. praticamente o dobro daquele do Grupo II. Veste grupo, só conceberam no "cio do potro" aquelas com número mais reduzido de lavagens uterinas. Esse aspecto não ficou claro nos resultados do Grupo I. onde se alcançou praticamente a mesma percentagem de éguats gestantes no "cio do potro" com I-3 ou com 4-6 lavagens uterinas.

Sabe-se que a infusão intra-ulerina de várias soluções, inclúindo solução fisiológica $0.9 \%$. nitrofurazona, iodopovidine e oxitetraciclina. bem como a colela da biópsia endometrial, provocam uma endometrite de grau variácl. desaparecendo dentro de 7 dias (WAELCHI el al.7. 1987).

Fica patente que essas alteraçoes não são tão evidentes quando se usal salina fisiológica (Grupo I). A diminuição significativa da laxal de prenhez no "cio do potro", neste grupo. pode estar ligada à contaminação bacteriana provocada pela lavagem. o que corrobora sugestão de NEFI.Y el al.5 (1983). de que a agressão leita ao endométrio alravés da lavagem uterina permite a introdução de bactérias que exacerbariam o processo inflamatório.

O uso de iodo-povidine possivelmente inibiria a ação das bactérias, indicando por que as laxas de prenhe 2 no Grupo II foram mais elevadas que no Grupo I. Então, as lesões inflamatórias provocadas pelas lavagens parecem ser a causa principal da diminuição dos índices de gestação no "cio do poero", conforme observações semelhantes de NEELY el al. ${ }^{5}$ (1983). ASBURY1 (1984) e WAELCHI el al.7 (1987). Os resultados indicaram queda notável das laxas de prenhe\% no "cio do potro" quando se utilizam sem qualquer critério as lavagens uterinas com $\mathrm{NaCl} 0.9 \%$ ou com iodo-povidine, estando de acordo com os resultados de McCUE: HUGHES3 (1990). Pontanto, devem-se iniciar an coberturas após o desaparecimento da reação inflamatória prejudicial aos gametas a aos embriões, que pode persistir além do $5^{\circ}$ dia pós-ovulação e induzir a luteólise. comprometendo o suporte progestágeno da prenlez (ASBURYI. 1984: WATSON\%, 1988). O iodo-povidine, em concentrações acima de $0.2 \%$ inibe a migração de neutrófilos in virro (WATSON8, 1987), entretanto, pode não exercer o mesmo efeito quando in vive.

Pode-se verificar que, apesalr de a retenção de placenta na égua ser um evento dramálico, uma profilaxia aldecpuada da metrite puerperal não só evita ou ameniza o desencadeamento de pododermalite puerperal tóxica como permite que ocorra a concepção nas éguas aletadas (Tàb. 2).

Ficou evidente que as lavagens uterinas podem comprometer a capacidade funcional do endométrio. Isso ficou confirmado também no caso das éguas com rêtenção de placenta, que apresentaram baixíssima incidência de prenhez no "cio do potro". em éguas lavadas com salina e em nenhuma com iodo-povidine. Apesar do reduzido número de éguas com Retentio secundinarum (Tab. 2). pode-se verilicar que no 20 c no $3^{\circ}$ cios p.p. essas éguas alcançaram níveis razoáveis de prenhez, especialmente aquelas lavadas com iodo-povidine. $75 \%$ de prenhe\% no $2^{\circ}$ cio p.p. Isso reforça a necessidade de um produto antibacteriano na lavagem uterina. devido à inevitável introdução de bactérias, não deixando o trabalho de limpeza lísica e bacteriana exclusivamente para o útero.

Conclui-se que as lavagens uterinas pós-parto diminuem os índices de prenhez no "cio do potro". e yue elas so devem ser empregadas quando houver conteúdo uterino patológico comprovado.

Sugere-se que não se manipule o endométrio após o $3^{\circ}$ ou $4^{\circ}$ dia pós-parto, porque a reação inllamatória estará presente durante o "cio do potro" o que levará. seguramente. a uma redução clas taxas de prenhez. Como tratamento auxiliar pode-se inclicar o descrito por LeBLANC2 (1994), através da aplicação de I0 UI de ocitocina intra-muscular para ạjudar na remoção do conteúdo uterino, mesmo naquelas éguas submetidas a lavagem uterina.

Pode-se sugerir, ainda, que toda égua com retenção de placenta deva ser submetida a uma correta e adequada limpeza uterina através de lavagem diária, evitando-se ou tentando-se evitar a toxemia. Com isso prescinde-se da cobertura no "cio do potro". mas garante-se uma involução uterina eficiente, podendo-se alcançar bons índices de prenhe\% no(s) cio(s) subseqüente(s). ou adiantar o aparecimento do $2^{\circ}$ cio pós-parto. conforme indicação de MERKT+ (1968).

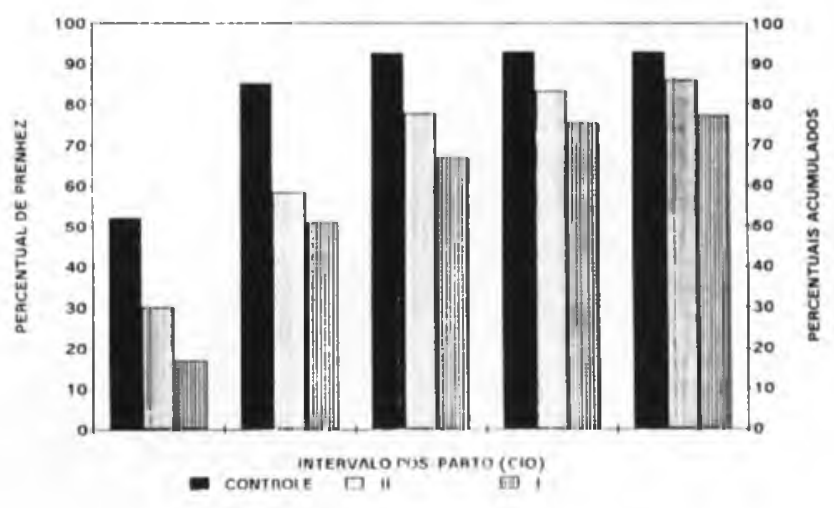

Percentuais acumulades de prenlez do l" ao 50 cio pes-parto exu éguas PSC. alojaldas no laras Santa Varia de Araras. São José dos Pinhais - PR. dos grupos Controle. das tratadas com iodo-povidine $0.4 \%$ e éguas tratadas com soluçāo salina (0.9\%. respectivamente. 


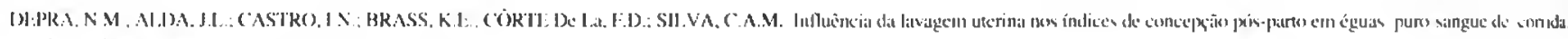

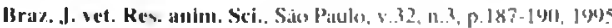

\begin{abstract}
SUMMARY
The effect of uterine lavage with a $0.9 \% \mathrm{VaCl}$ or $0.4 \%$ povidine iodine solution was evaluated on the foal heall conception rate of 93 thoroughbred mares. Their conception rate were compared to the conception rate of 27 Thoroughbred mares without any manipulation of the uterus. Another 15 mares with p.p. retained placenta were submited to uterine lavage with the same solutions and their reproductive performance were accompanied. It was observed that the p.p. uterine lavage. independent of the solution used, impaired the uterine involution and the conception rates: beciuse of its inflammitory action it is suggested that the uterine lavage could be indicalted only in mares with retained placenta and. if the procedure is performed until day 3 or + alter foraling.
\end{abstract}

UNITERMS: Mares; Uerina flushing. Post-partum: Conception

\title{
REFERÊNCIAS BIBLIOGRÁFICAS
}

I-ASBURY, A.C. Uterine mechanisms in the mare: the use of intratuterine plasma in the management of endometritis. Theriogenology, v.21, n.2, p.39-43, 1984.

2-L.eBL.ANC. M.M. Oxytocin - The new wonder drug for treatment of endometritis. Equine Veterinary Educating. v.6. n.1, p.39-43. 1994.

3-McCUE. P.M.: HLGHES. J.P. The effect of post-partum uterine lavage on foal heat pregnancy rate. Theriogenology, v.33, n.6, p.1121-9, 1990).

4-MERK T, H. Bericht uber dic Herbstuntersuchung 1967. Hipologische Blatter, Beilage Nr. 135 zur Sportwelt. v.24. 1968

5-NFEI.Y. D.P.: LIU, K.M.I.: HILI.MANN, R.B. Equine reproduction. New Jersey. Hoffman - La Roche. 1983.
6-SALTILL, A.: GUTIERREZ. A.: BLEN-LLADO. ㅅ.: SOSA, C. Cervicoendometrial cylology and physiological aspects of the post-partum mare. Journal Reproduction and Fertility, v.35, p.305-9, 1987 (Supplement).

7-WAELCHI, R.D.; CORIOUBEZ, L.: WINDER. N.C. Effect of intrauterine plasma infusion in the mare: histological, bacteriological and cytological findings. Theriogenology, v.28, n.6, p.861-9. 1987.

8-WATSON, E.D. Effect of povidone-iodine on in vitro locomotion of equine neutrophils. Equine Veterinary Journal, v. 19, n.3, p.226-8, 1987.

9-WATSON, E.D. Uterine defense mechanisms in mars resistant and susceptible to persistent endometritis: a review. Equine Veterinary Journal. v.20. n.6, p.397-400), 1988.

Recebido para publicação em $02 / 05 / 94$ Aprovado para publicação em 02/11/94 